\title{
Sensitive Determination of Gliclazide in Tablets and Urine Using Modified Screen-Printed Electrodes
}

\author{
Somayeh Tajik ${ }^{1, *}$, Sayed Zia Mohammadi ${ }^{2}$ and Hadi Beitollahi ${ }^{3}$ \\ ${ }^{I}$ NanoBioElectrochemistry Research Center, Bam University of Medical Sciences, Bam, Iran \\ ${ }^{2}$ Department of Chemistry, Payame Noor University, Tehran, Iran \\ ${ }^{3}$ Environment Department, Institute of Science and High Technology and Environmental \\ Sciences, Graduate University of Advanced Technology, Kerman, Iran \\ *Corresponding author: tajik_s1365@yahoo.com
}

Received October 5, 2018; Accepted December 10, 2020

https://doi.org/10.4152/pea.2021390404

\begin{abstract}
In the present work, a simple and low-cost protocol for determination of gliclazide using modified screen-printed electrodes (SPE) was reported. The immobilization of magnetic core-shell manganese ferrite nanoparticles (MCSNP) onto SPE provides a unique opportunity for charge transfer process. Consequently, the electroanalytical sensing of gliclazide was explored at the modified SPE surface. The response of the modified electrode was linear, in the concentration range from 0.5 to $300.0 \mu \mathrm{M}$, and a detection limit of $100 \mathrm{nM}$ was obtained. The proposed method was successfully employed for gliclazide determination in pharmaceutical and human urine samples. The method showed tremendous reproducibility and intra- and inter-day stability, and has proved to be highly reliable for gliclazide analysis in clinical samples.
\end{abstract}

Keywords: Gliclazide determination, magnetic core shell nanoparticles, screen-printed carbon electrode, voltammetry.

\section{Introduction}

Determination of drugs in biological matrices requires the development of reliable analytical methods in clinical, industrial and research contexts. These analyses are essential in pharmacokinetic studies and therapeutic monitoring of drugs [1].

Type II diabetes is a metabolic disorder characterized by hyperglycemia, due to cellular resistance to insulin, combined with insufficient pancreatic secretion of insulin. Over 300 million people suffer from diabetes worldwide [2].

Gliclazide (GLZ) is a second-generation sulfonylurea oral anti-diabetic drug, effective in controlling blood glucose in type II diabetes mellitus. It acts mainly on pancreatic sulfonylurea receptors (SURs), at the surface of $\beta$-cells, by increasing the secretion of insulin [3].

In contrast with the first-generation drugs, gliclazide preparations are highly efficient, thus, treatment doses are two to three times lower [4]. Therefore, the 
development of simple new analytical methods with better specificity and higher sensitivity is very important [5].

Many methods for gliclazide determination in pharmaceuticals are described in literature. An important group consists of UV and visible spectrophotometric methods $[6,7]$.

Chromatographic methods, including liquid chromatography [8-10], thin-layer chromatography $[11,12]$ and gas chromatography [13], were also proven to be useful.

Comparatively, only few reports dealing with the electrochemical behavior of gliclazide and its electro-analytical determination using voltammetry [14-16] were published.

There are some advantages of the electrochemical methods, including simplicity, low cost, high sensitivity and miniaturization [17]. The development of screenprinted electrodes (SPEs) has become a major revolution in the construction of electrochemical sensors/biosensors [18]. SPEs have been designed especially for miniaturization of electrochemical analytical systems [19].

SPEs are highly-versatile, easy to use, cost-effective analytical tools and also suitable to miniaturization [20]. Furthermore, unlike conventional electrodes, such as glassy carbon electrode, SPEs avoid the cleaning process [21].

Nowadays, the development of new materials capable to change the electrode surface with better analytical properties, including graphene, nanoparticles, and carbon nanotubes [22-25], is of interest.

Nanomaterials, because of their unique properties, have been extensively developed, since they can act as conduction centers, facilitating the transfer of electrons and providing great catalytic surface areas [26-31].

In current years, multifunctional nanomaterials became a rich source for researchers in the field of nanotechnology, due to their enormous and wide application in the area of biomedical analysis [32] and sensing [33]. Among various types of multifunctional nanomaterials, core@shell nano-particles are the most popular, because of their dual characteristics. These particles consist of a core (the central component) and a shell (the outer component); they not only retain the characteristics of each component, but also possess unique advantages with enhanced properties [33].

In addition to the improved material properties, core@shell materials are also important from the economic point of view, e.g., one can coat an inexpensive material on lavish core material to shield it against harsh conditions or to improve its properties [34].

The technological importance of nanoparticles has driven efforts to fabricate novel core/shell nanomaterials, which are of fundamental interest to modern materials science, due to their vast applications in controlled drug release, magnetic drug targeting, inhibition of microbial biofilm growth, biosensors, antimicrobial therapy or medical diagnosis [35].

In the present work, magnetic core-shell manganese ferrite nanoparticles (MCSNP) [36] were synthesized, to modify screen printed carbon electrodes. To the best of our knowledge, so far no study has been reported on the determination of gliclazide by using MCSNP/SPCE. 


\section{Experimental}

\section{Apparatus and chemicals}

The electrochemical measurements were performed by using an Autolab potentiostat/galvanostat (PGSTAT 302N, Eco Chemie, the Netherlands). The pH values were measured using a pH-meter (Metrohm 692 model, Herisau, Switzerland).

Gliclazide and all chemicals had analytical purity (Merck, Darmstadt, Germany). The phosphate buffer solution (PBS) was produced from concentrate phosphoric acid and its salts. As previously published, we synthesized the magnetic core-shell manganese ferrite NPs in our lab [36].

\section{Preparation of the electrode}

The bare screen-printed electrode was coated with MCSNP, as follows. A stock solution of MCSNP in $1 \mathrm{~mL}$ aqueous solution was prepared by dispersing $1 \mathrm{mg}$ of MCSNP with ultrasonication for $1 \mathrm{~h}$. Then, $2 \mu \mathrm{L}$ of the MCSNP/ $\mathrm{H}_{2} \mathrm{O}$ suspension solution were casted on the carbon working electrode, until the solvent was evaporated at the room temperature.

\section{Preparation of real samples}

Ten tablets of GLZ (labeled $80.0 \mathrm{mg}$ per each tablet) were completely grounded and homogenized, accurately weighed and dissolved with ultrasonication in $20 \mathrm{~mL}$ of water. Finally, the mixture was filtered and the clear filtrate was transferred into a $100 \mathrm{~mL}$ volumetric flask and diluted to the mark using 0.1 M PBS with $\mathrm{pH}$ 7.0. Finally, a suitable volume of the resultant solution was transferred to the electrochemical cell, and the resulting solution was used for GLZ analysis. The sample was spiked with different amounts of GLZ, and the content was analyzed by using the standard addition method, in order to prevent any matrix effect.

Urine samples, immediately after collection, were stored in a refrigerator. Twenty milliliters of the sample were centrifuged for $10 \mathrm{~min}$, at $3000 \mathrm{rpm}$. The supernatant was filtered using a $0.45 \mu \mathrm{m}$ filter. In order to prevent any matrix effect, the standard addition method was used for GLZ analysis in the urine. For this purpose, a suitable volume of the solution was transferred into some $50 \mathrm{~mL}$ volumetric flasks, spiked with different amounts of GLZ and diluted to the mark with PBS $(\mathrm{pH} \mathrm{7.0)}$.

\section{Results and discussion}

\section{Electrochemical behavior of gliclazide at the MCSNP/SPCE surface}

The $\mathrm{pH}$ value of the aqueous solution is effective on GLZ electrochemical behaviour. Therefore, the solution $\mathrm{pH}$ was optimized to obtain highly accurate results for GLZ electro-oxidation. Accordingly, GLZ electrochemical behaviour at the MCSNP/SPCE surface was studied by voltammetry, in $0.1 \mathrm{M} \mathrm{PBS}$, at $\mathrm{pH}$ values from 3.0 to 9.0. It was revealed that neither acidic nor basic media were appropriate for GLZ electro-oxidation at the MCSNP/SPCE surface, and the best results were obtained at neutral conditions (Fig. 1). Thus, the $\mathrm{pH} 7.0$ was chosen as optimum for GLZ electro-oxidation at the MCSNP/SPCE surface. 


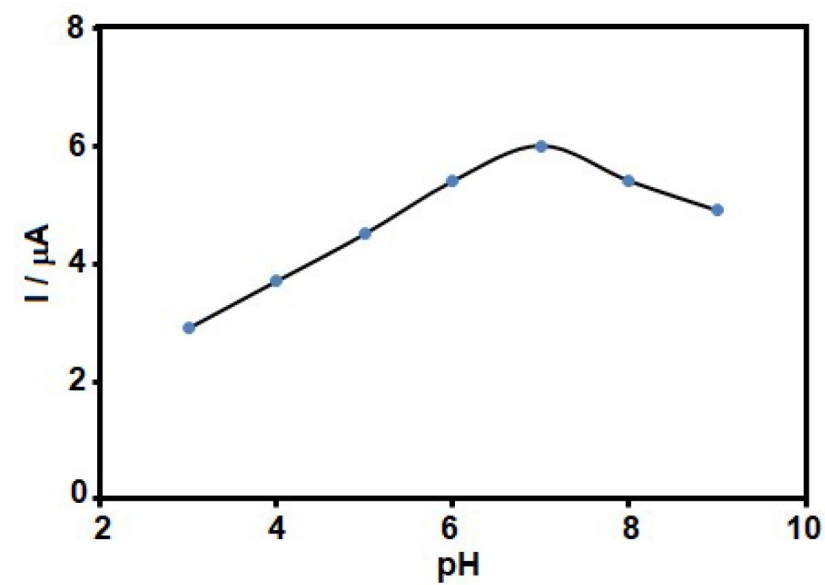

Figure 1. GLZ electro-oxidation current at the MCSNP/SPCE surface, in the presence of $80.0 \mu \mathrm{M}$ GLZ, at various buffered pHs (3-9).

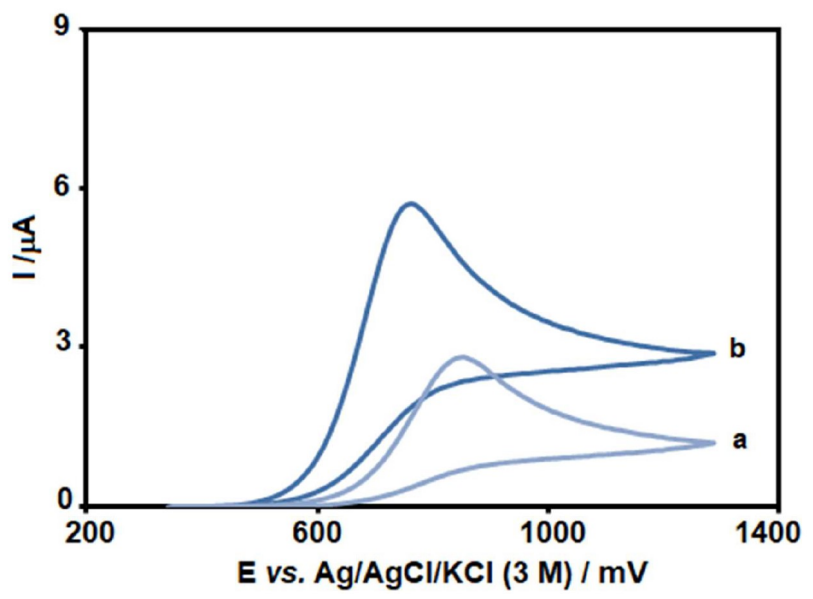

Figure 2. Voltammograms of (a) unmodified SPCE and (b) MCSNP/SPCE, in the presence of $80.0 \mu \mathrm{M}$ GLZ, at $\mathrm{pH} 7$ (at $50 \mathrm{mV} / \mathrm{s}$ ).

Fig. 2 depicts the $\mathrm{CV}$ responses for $80.0 \mu \mathrm{M}$ GLZ electro-oxidation at unmodified SPCE (curve a) and MCSNP/SPCE (curve b) surfaces. The peak potential, due to GLZ oxidation, occurred at $760 \mathrm{mV}$, which is about $90 \mathrm{mV}$ more negative than that of the unmodified SPCE.

Also, the anodic peak current for GLZ oxidation at the MCSNP/SPCE surface is much higher, in comparison with that of the unmodified SPCE, thus indicating effectiveness of SPCE modification with MCSNP, in the GLZ oxidation process.

\section{Effect of scan rate}

LSV was used to evaluate the scan rate effect on GLZ electrocatalytic oxidation at the MCSNP/SPCE surface (Fig. 3). The results indicated that, with an increase in the scan rate, the oxidation peak potential shifted towards higher positive potentials. This shows the kinetic restriction in the electrochemical reaction. In addition, a linear plot of peak current $\left(\mathrm{I}_{\mathrm{p}}\right)$, versus the square root of scan rate $\left(\mathrm{v}^{1 / 2}\right)$, was observed at the scan rate values from 5 to $1000 \mathrm{mV} / \mathrm{s}$. This means that the process is diffusion rather than surface control at sufficient overpotential [37]. 


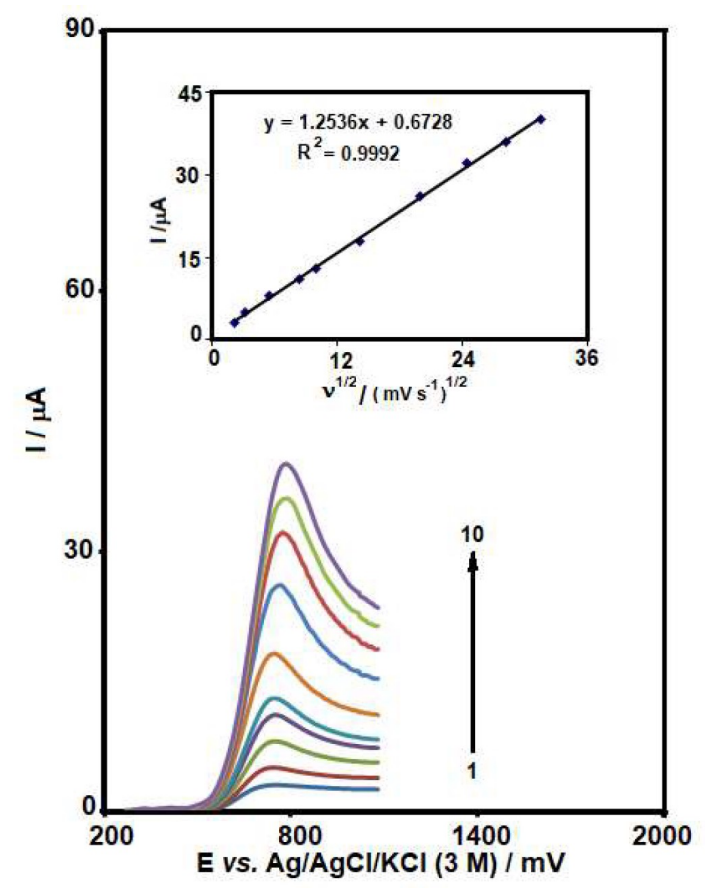

Figure 3. LSVs of MCSNP/SPCE in 0.1 M PBS (pH 7.0), containing 40.0 $\mu \mathrm{M}$ GLZ, at various scan rates; numbers 1 - 10 correspond to $5,10,30,70,100,200,400,600,800$ and $1000 \mathrm{mV} / \mathrm{s}$, respectively. Inset: variation of anodic peak current $v s$. square root of scan rate.

\section{Chronoamperometric measurements}

For GLZ chronoamperometry study at the MCSNP/SPCE surface, the working electrode potential was set at $0.95 \mathrm{~V}$ versus $\mathrm{Ag} / \mathrm{AgCl} / \mathrm{KCl}(3.0 \mathrm{M})$, at different GLZ concentrations, in $0.1 \mathrm{M}$ PBS ( $\mathrm{pH}$ 7.0) (Fig. 4). According to the Cottrell equation, the current of the electrochemical reaction, which is an electroactive material at the mass transport limited condition, can be seen in equation (1) [37].

$$
\mathrm{I}=\mathrm{nFAD}{ }^{1 / 2} \mathrm{C}_{\mathrm{b}} \pi^{-1 / 2} \mathrm{t}^{-1 / 2}
$$

where $\mathrm{I}$ is current (A), $\mathrm{n}$ is the number of electrons, $\mathrm{F}$ is Faraday constant $(96485$ $\mathrm{C} / \mathrm{mol}), \mathrm{A}$ is the electrode area $\left(\mathrm{cm}^{2}\right), \mathrm{D}$ is the diffusion coefficient $\left(\mathrm{cm}^{2} / \mathrm{s}\right), \mathrm{t}$ is time $(\mathrm{sec})$ and $\mathrm{C}_{\mathrm{b}}$ is the bulk concentration $\left(\mathrm{mol} / \mathrm{cm}^{3}\right)$. According to the Cottrell equation, at different GLZ concentrations, diagrams of I vs. $\mathrm{t}^{-1 / 2}$ were drew (Fig. $4 a)$. Then, the slopes of the obtained lines were plotted vs. GLZ concentration (Fig. 4b). From the obtained slope and from the Cottrell equation, the mean value of $\mathrm{D}$ for GLZ was determined as $1.1 \times 10^{-5} \mathrm{~cm}^{2} / \mathrm{s}$.

\section{Calibration plots and limits of detection}

The linearity of the peak current of GLZ oxidation on the MCSNP/SPCE surface was assessed using SWV experiment (initial potential $=0.47 \mathrm{~V}$, end potential $=0.95$ $\mathrm{V}$, step potential $=0.002 \mathrm{~V}$, modulation amplitude $=0.01995 \mathrm{~V})$, in $0.1 \mathrm{M}$ PBS $(\mathrm{pH}=7.0)$, with different GLZ concentrations. 


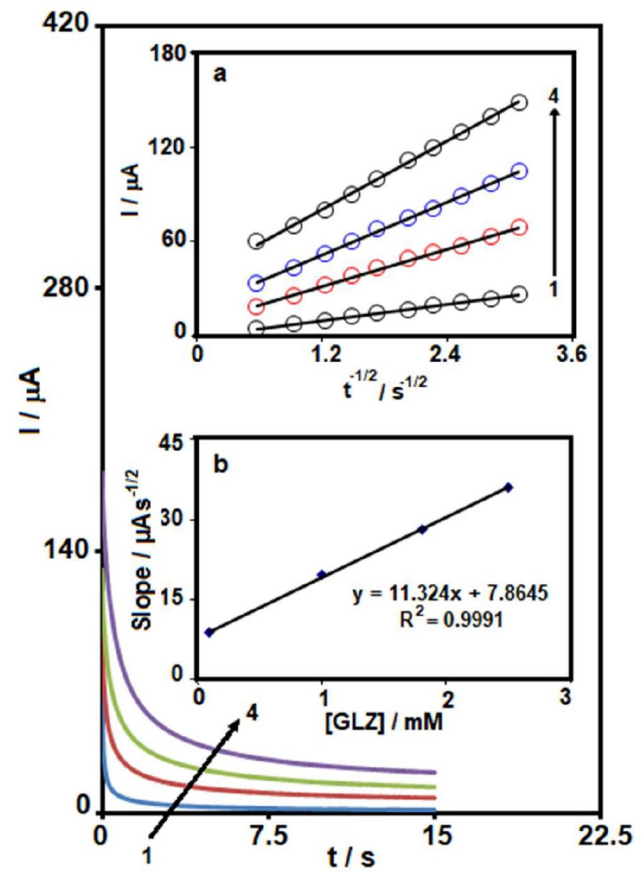

Figure 4. Chronoamperograms obtained at MCSNP/SPCE, in $0.1 \mathrm{M}$ PBS (pH 7.0), with different GLZ concentrations. The numbers $1-4$ correspond to $0.1,1,1.8$ and $2.5 \mathrm{mM}$ of GLZ. Insets: (a) Plots of I vs. $\mathrm{t}^{-1 / 2}$ obtained from chronoamperograms $1-4$; and (b) Plot of the slope of the straight lines against GLZ concentration.

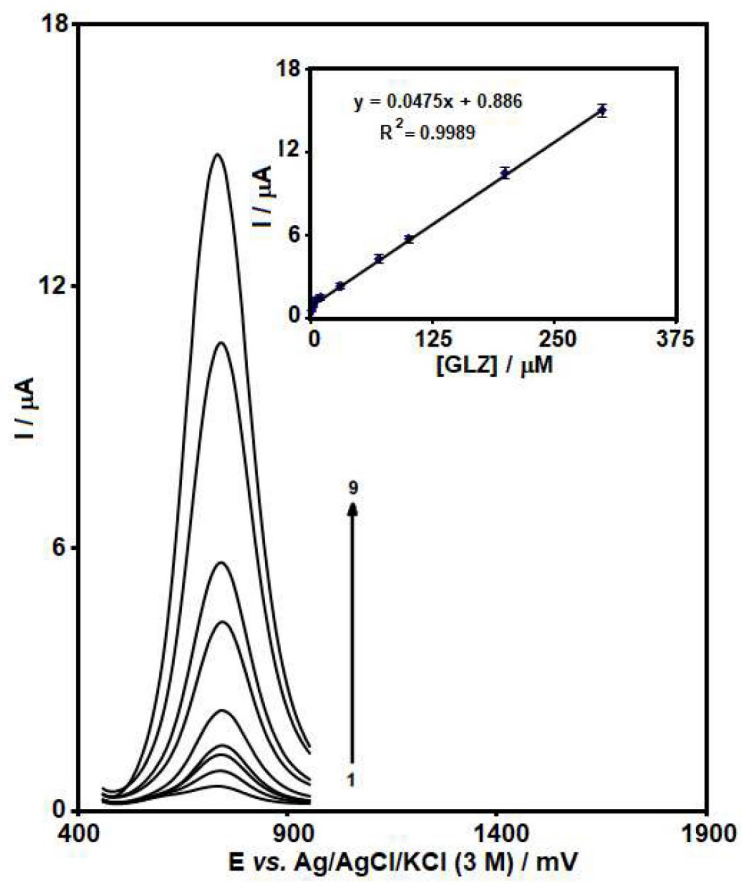

Figure 5. SWVs of MCSNP/SPCE, in 0.1 M PBS ( $\mathrm{pH} 7.0$ ), containing different GLZ concentrations $(0.5,2.5,5.0,10.0,30.0,70.0,100.0,200.0$ and $300.0 \mu \mathrm{M})$. Inset: the plot of the peak current as a function of GLZ concentration is in the range from 0.5 to 300.0 $\mu \mathrm{M}$.

The results shown in Fig. 5 reveal that, at the MCSNP/SPCE surface, there is a linear dependency between GLZ oxidation electrocatalytic peak current and its 
concentration within the range from $5.0 \times 10^{-7}$ to $3.0 \times 10^{-4} \mathrm{M}$. The detected limit, on the basis of three times the standard deviation $(3 \sigma)$ of the blank, was $1.0 \times 10^{-7}$ M. Based on our knowledge, there is only one electrochemical work on GLZ determination, and most of these methods are HPLC and GC. Therefore, our obtained results are compared with some of them (see Table 1).

Table 1. Efficiency comparison of some methods used in GLZ detection.

\begin{tabular}{|l|c|c|c|c|}
\hline \multicolumn{1}{|c|}{ Method } & $\begin{array}{c}\text { Analysis time } \\
\text { (min) }\end{array}$ & LOD & LDR & Ref. \\
\hline $\begin{array}{l}\text { Dispersive liquid-liquid } \\
\text { microextraction-HPLC }\end{array}$ & $>20$ & $0.045 \mathrm{mg} / \mathrm{L}$ & $0.12-2.8 \mathrm{mg} / \mathrm{L}$ & {$[2]$} \\
\hline $\begin{array}{l}\text { Spectrophotometric } \\
\text { determination }\end{array}$ & $>30$ & $0.05 \mathrm{mg} / \mathrm{L}$ & $0.5-4 \mathrm{mg} / \mathrm{L}$ & {$[6]$} \\
\hline HPLC & $>10$ & $30 \mathrm{ng} / \mathrm{mL}$ & $75-10000 \mathrm{ng} / \mathrm{mL}$ & {$[8]$} \\
\hline $\begin{array}{l}\text { Electrochemical using glassy } \\
\text { carbon electrode }\end{array}$ & 6 & $1.2 \times 10^{-5} \mu \mathrm{M}$ & $5 \times 10^{-6}-4 \times 10^{-4} \mu \mathrm{M}$ & {$[16]$} \\
\hline $\begin{array}{l}\text { HPLC with electrochemical } \\
\text { detection }\end{array}$ & $>20$ & $0.01 \mu \mathrm{M}$ & $0.05-4 \mu \mathrm{M}$ & {$[38]$} \\
\hline HPLC Gradient & $>20$ & ----- & $2-12 \mathrm{mg} / \mathrm{L}$ & {$[39]$} \\
\hline $\begin{array}{l}\text { Electrochemical using a } \\
\text { screen printed electrode }\end{array}$ & $<1$ & $0.1 \mu \mathrm{M}$ & $0.5-300 \mu \mathrm{M}$ & This work \\
\hline
\end{tabular}

\section{Real sample analysis}

Finally, MCSNP/SPCE was applied for GLZ determination in a GLZ tablet and in urine samples. For this purpose, GLZ determination in the real samples was carried out (Table 2).

Table 2. The application of MCSNP/SPE for GLZ determination in real samples $(n=5)$.

\begin{tabular}{|c|c|c|c|c|}
\hline Sample & $\begin{array}{c}\text { Spiked } \\
\boldsymbol{\mu M}\end{array}$ & $\begin{array}{c}\text { Found } \\
\boldsymbol{\mu M}\end{array}$ & $\begin{array}{c}\text { Recovery } \\
\mathbf{\%}\end{array}$ & $\begin{array}{c}\text { RSD } \\
\mathbf{\%}\end{array}$ \\
\hline \multirow{4}{*}{ GLZ tablet } & 0.0 & 20.0 & --- & 2.7 \\
\cline { 2 - 5 } & 5.0 & 25.1 & 102.0 & 2.6 \\
\cline { 2 - 5 } & 10.0 & 30.3 & 103.0 & 3.0 \\
\cline { 2 - 5 } & 20.0 & 39.5 & 97.5 & 3.1 \\
\hline \multirow{3}{*}{ Urine } & 0 & Not detected & --- & 3.2 \\
\cline { 2 - 5 } & 10.0 & 10.1 & 101.0 & 3.1 \\
\cline { 2 - 5 } & 20.0 & 19.8 & 99.0 & 2.4 \\
\cline { 2 - 5 } & 30.0 & 29.3 & 97.7 & 2.7 \\
\hline
\end{tabular}

Also, the recovery of known amounts of GLZ from spiked samples was assessed. The results show the added GLZ that was quantitatively recovered from the real sample, and demonstrate MCSNP/SPCE applicability for GLZ determination in the real samples. Also, RSD mean indicates that the method is reproducible.

The amount of GLZ in the tablet was found to be $79.63 \mathrm{mg} / \mathrm{tablet}$. It was discovered that there is no significant difference between MCSNP/SPCE results and the nominal value on the tablet label $(80.0 \mathrm{mg} /$ tablet $)$. The t-test was applied 
to the result, and showed that there was no significant difference, at $95 \%$ confidence level.

\section{Conclusion}

In this work, by employing magnetic core shell nanoparticles for SPCEs modification, a novel sensor that provides a sensitive method for GLZ determination has been developed. The proposed protocol demonstrated herein is a novel, simple, portable, inexpensive and easy-to-use fabrication method, for the determination of GLZ concentration in tablets and urine samples, with good analytical performance. Due to the unique properties of magnetic core shell nanoparticles, the sensor exhibited a remarkable electrochemical activity towards GLZ oxidation. Under optimized conditions, SWV exhibited linear dynamic ranges from 0.5 to $300 \mu \mathrm{M}$, with a detection limit of $100.0 \mathrm{nM}$.

\section{Acknowledgements}

The authors wish to thank Payame Noor University for supporting this work.

\section{References}

1. Vasconcelos I, Fernandes C. Magnetic solid phase extraction for determination of drugs in biological matrices. Trends Anal Chem. 2017;89:4152. https://doi.org/10.1016/j.trac.2016.11.011.

2. Monzon CM, Teglia CM, Delfino MR, et al. Chemometric optimization and validation of a novel dispersive liquid-liquid microextraction-HPLC method for gliclazide, glibenclamide and glimepiride quantitation in serum samples. Microchem $\mathrm{J}$. 2016;127:113-119. https://doi.org/10.1016/j.microc.2016.02.011.

3. Chen L, Yu F, Zeng TS, et al. Effects of gliclazide onendothelial function in patients with newly diagnosed type 2 diabetes. Eur J Pharm. 2011;659:296301. https://doi.org/10.1016/j.ejphar.2011.02.044.

4. Al-Kassas RS, Al-Gohary OMN, Al-Faadhel MM. Controlling of systemicabsorption of gliclazide through incorporation into alginate beads. Int J Pharm. 2007;341:230-237. https://doi.org/10.1016/j.ijpharm.2007.03.047.

5. Barzegar-Jalali M, Valizadeh H, Siahi Shadbad MR, et al. Cogrinding as an approach to enhancedissolution rate of a poorly water-soluble drug (gliclazide). Powder $\quad$ Tech. 2010;197:150-158. https://doi.org/10.1016/j.powtec.2009.09.008.

6. El-Enany N. Spectrophotometric determination of gliclazide in pharmaceuticals and biological fluids through ternary complex formation with eosin andpalladium (II). II Farmaco. 2004;59:63-69. https://doi.org/10.1016/j.farmac.2003.08.007.

7. Emara KM, Mohamed AMI, Askal HF, et al. Spectrophotometric determination of some pharmaceutical compounds using 2,2-diphenyl-1picrylhydrazyl. Anal Letters. https://doi.org/10.1080/00032719308017478.

$1993 ; 26: 2385-2395$. 
8. Rouini MR, Mohajer A, Tahami MH. A simple and sensitive HPLC method for determination of gliclazide in human serum. J Chrom B: Biomed Sci Appl. 2002;785:383-386. https://doi.org/10.1016/S1570-0232(02)00951-0.

9. Foroutan SM, Zargihi A, Shafatti A, et al. Application of monolithic column in quantification of gliclazide in human plasma by liquid chromatography. $\mathrm{J}$ Pharm Biomed Anal. 2006;42:513-516. https://doi.org/10.1016/j.jpba.2006.05.003.

10. Bansal G. Forced degradation study on gliclazide and application of validated stability indicating HPLC-UV method in stability testing of gliclazide tablets. Chromat. 2007;66:9-10. https://doi.org/10.1365/s10337-007-0394-4.

11. Gumieniczek A, Berecka A. Quantitative analysis of gliclazide and glipizidein tablets by a new validated and stability-indicating RPTLC method. J Planar Chromato. 2010;23:129-133, 2010. https://doi.org/10.1556/JPC.23.2010.2.8.

12. Havele S, Dhaneshwar S. Simultaneous determination of metforminhydrochloride in its multicomponent dosage forms with sulfonyl ureas likegliclazide and glimeperide using HPTLC. J Liquid Chrom Related Tech. 2011;34:966-980. https://doi.org/10.1080/10826076.2011.557465.

13. Maeda T, Yamaguchi T, Hashimoto M. Gas chromatographic determination of the hypoglycaemic agent gliclazide in plasma. J Chromato. 1981;223:357-363. https://doi.org/10.1016/S0378-4347(00)80108-5.

14. Radi AE, Eissa S. Electrochemical Study of Gliclazide and Its Complexation with $\quad \beta \quad$ Cyclodextrin. Electroanalysis. 2010;22:2991-2996. https://doi.org/10.1002/elan.201000416.

15. Radi A, El-ries MA, Bekhiet GE. Electrochemical oxidation of the hypoglycaemic drug gliclazide. Anal Letters. 1999;32:1603-1612. https://doi.org/10.1080/00032719908542919.

16. Hrichi H, Louhaichi MR, Monser L, et al. Gliclazide voltammetric sensor based on electropolymerizedmolecularly imprinted polypyrrole film onto glassy carbon electrode. Sensors Actuators B: Chemical. 2014;204:42-49. https://doi.org/10.1016/j.snb.2014.07.056.

17. Beitollahi $\mathrm{H}$, Karimi-Maleh $\mathrm{H}$, Khabazzadeh $\mathrm{H}$. Nanomolar and selective determination of epinephrine in the presence of norepinephrine using carbon paste electrode modified with carbon nanotubes and novel 2-(4-oxo-3-phenyl3,4-dihydro-quinazolinyl)-N'-phenyl-hydrazinecarbothioamide. Anal Chem. 2008;80:9848-9851. https://doi.org/10.1021/ac801854j.

18. Cumba LR, Smith JP, Zuway KY, et al. Forensic electrochemistry: Simultaneous voltammetric detection of MDMA and its fatal counterpart "dr Death" (PMA). Anal Methods. 2016;8:142-152. https://doi.org/10.1039/C5AY02924D.

19. Chan KF, Lim HN, Shams N, et al. Fabrication of graphene/gold-modified screen-printed electrode for detection of carcinoembryonic antigen. Mater Sci Eng: C. 2016;58:666-674. https://doi.org/10.1016/j.msec.2015.09.010.

20. Chatzipetrou M, Milano F, Giotta L, et al. Functionalization of gold screen printed electrodes with bacterial photosynthetic reaction centers by laser printing technology for mediatorless herbicide biosensing. Electrochem Communic. 2016;64:46-50. https://doi.org/10.1016/j.elecom.2016.01.008. 
21. Lezi N, Economou A, Barek J, et al. Screen Printed Disposable Sensors Modified with Bismuth Precursors for Rapid Voltammetric Determination of 3 Ecotoxic Nitrophenols. Electroanalysis. 2014;26:766-775. https://doi.org/10.1002/elan.201400001.

22. Parvin MH. Graphene paste electrode for detection of chlorpromazine. Electrochem Comm. 2011;13:366-369. https://doi.org/10.1016/j.elecom.2011.01.027.

23. Mahmoud KA, Hrapovic S, Luong JHT. Picomolar Detection of Protease Using Peptide/Single Walled Carbon Nanotube/Gold Nanoparticle-Modified Electrode. ACS Nano. 2008;2:1051-1057. https://doi.org/10.1021/nn8000774.

24. Mohammadi SZ, Beitollahi H, Jasemi M, et al. Nanomolar Determination of Methyldopa in the Presence of Large Amounts of Hydrochlorothiazide Using a Carbon Paste Electrode Modified with Graphene Oxide Nanosheets and 3-(4'Amino-3'-hydroxy-biphenyl-4-yl)acrylic Acid. Electroanalysis. 2015;27:24212430. https://doi.org/10.1002/elan.201500245.

25. Beitollahi H, Ghofrani Ivari S, Torkzadeh Mahani M. Voltammetric determination of 6-thioguanine and folic acid using a carbon paste electrode modified with $\mathrm{ZnO}-\mathrm{CuO}$ nanoplates and modifier. Mater Sci Eng: C. 2016;69:128-133. https://doi.org/10.1016/j.msec.2016.06.064.

26. Kong L, Jiang X, Zeng Y, et al. Molecularly imprinted sensor based on electropolmerized poly(o-phenylenediamine) membranes at reduced graphene oxide modified electrode for imidacloprid determination. Sensors Actuators B: Chemical. 2013;185:424-431. https://doi.org/10.1016/j.snb.2013.05.033.

27. Jahani SH, Beitollahi H. Selective detection of dopamine in the presence of uric acid using $\mathrm{NiO}$ nanoparticles decorated on graphene nanosheets modified screenprinted electrodes. Electroanalysis. 2016;28:2022-2028. https://doi.org/10.1002/elan.201501136.

28. Mohammadi SZ, Beitollahi H, Bani Asadi E.. Electrochemical determination of hydrazine using a $\mathrm{ZrO}_{2}$ nanoparticles-modified carbon paste electrode. Env Monit Assess. 2015;187:122-132. https://doi.org/10.1007/s10661-015-4309-9.

29. Mohammadi SZ, Beitollahi H, Mousavi M. Determination of Hydroxylamine Using a Carbon Paste Electrode Modified with Graphene Oxide Nano Sheet. Russian Electrochem. 2017;53:374-379. https://doi.org/10.1134/S1023193517040097.

30. Zhang Y, Suryanarayanan V, Nakazawa I, et al. Electrochemical behavior of Au nanoparticle deposited on as-grown and O-terminated diamond electrodes for oxygen reduction in alkaline solution. Electrochim Acta. 2004;49:52355240. https://doi.org/10.1016/j.electacta.2004.07.005.

31. Mohammadi SZ, Beitollahi H, Fadaeian H. Voltammetric Determination of Isoproterenol using a Graphene Oxide Nano Sheets Paste Electrode. J Anal Chem. 2018;73:705-712. https://doi.org/10.1134/S1061934818070122.

32. Jia F, Liu X, Li L, et al. Multifunctional nanoparticles for targeted delivery of immune activating and cancer therapeutic agents. J Control Release 2013;172:1020-1034. https://doi.org/10.1016/j.jconrel.2013.10.012. 
33. Chatterjee K, Sarkar S, Rao KJ, et al. Core/shell nanoparticles in biomedical applications. Adv Colloid Interface Sci. 2014;209;8-39. https://doi.org/10.1016/j.cis.2013.12.008.

34. Patra S, Roy E, Madhuri R, et al. An imprinted $\mathrm{Ag} @ \mathrm{CdS}$ core shell nanoparticle based optical-electrochemical dual probe for trace level recognition of ferritin. Biosensors Bioelectronics. 2015;63:301-310. https://doi.org/10.1016/j.bios.2014.07.063.

35. Cristescua R, Popescu C, Socol G, et al. Magnetic core/shell nanoparticle thin films deposited by MAPLE: Investigation by chemical, morphological and in vitro biological assays. Appl Surf Sci. 2012;258:9250-9255. https://doi.org/10.1016/j.apsusc.2012.02.055.

36. Mohammadi SZ, Seyedi A. Preconcentration of cadmium and copper ions on magnetic core-shell nanoparticles for determination by flame atomic absorption. Environ Toxicolo and Chem. 2015;98:705-713. https://doi.org/10.1080/02772248.2015.1134530.

37. Bard AJ, Faulkner LR. "Electrochemical Methods: Fundamentals and Applications." 2nd Ed. New York:Wiley;2001.

38. Kuo $\mathrm{C}-\mathrm{Y}$, Wu S-M. High-performance liquid chromatography with electrochemical detection for analysis of gliclazide in plasma. J Chromato. A. 2005;1088:131-135. https://doi.org/10.1016/j.chroma.2004.12.097.

39. Baghel US, Shrivastava B, Kumar D, et al.. Gradient HPLC method development and validation for Simultaneous estimation of Rosiglitazone and Gliclazide. Asian Pacific J Tropical Disease. 2012;2:S756-S760. https://doi.org/10.1016/S2222-1808(12)60259-X. 